\title{
DIE VERHOUDING TUSSEN DIE OU EN NUWE TESTAMENT IN DIE HERMENEUTIEK
}

\author{
PROF. DR. W. C. VAN WYK
}

Hierdie artikel is 'n verwerking van 'n voordrag voor die Pretoriase Predikante Broederkring wat gedurende die eerste semester van 1971 gehou is. Dit was bedoel as 'n inleiding tot 'n diskussie oor die Hermeneutiek van die Ou Testament. Uit hierdie diskussie het die referate van ds. J. A. Loader oor die hantering van motiewe in die Ou Testament en van ds. A. P. B. Breytenbach oor die tipologiese uitleg van die Ou Testament voortgevloei. Uit so 'n opset is dit vanselfsprekend dat dié artikel nie ' $n$ volledige en sistematiese uiteensetting van die Ou Testamentiese Hermeneutiek kan of wil wees nie. 'n Paar tipiese en in die oog springende interpretasiewyses is aangestip en aan die hand van die werk van 'n verteenwoordiger van die rigting behandel. Die volgende interpretasies kom onder die soeklig:

1. Die Christologiese (W. Vischer),

2. Die Eksistensialistiese (R. Bultmann),

3. Die Godsdienshistoriese en „Frömmigkeitsgeschichtliche” (Fr.

Baumgärtel), en

4. Die „Teologiese” (J. Bright).

By al hierdie benaderingswyse gaan dit wesenlik om die vraag van die verhouding van die Ou en die Nuwe Testament.

\section{DIE CHRISTOLOGIESE INTERPRETASIE:}

Sowel Karl Barth as Wilhelm Vischer het die Ou Testament as getuie van Jesus Christus interpreteer, hoewel elkeen op sy eie wyse. Hiervolgens geld die openbaring van God in die Ou Testament vir die kerk, maar dit is alleen duidelik vanuit die Nuwe Testament. Slegs die kerk kan die Ou Testament reg lees. As getuie van die koms van Christus is die Ou Testament van betekenis vir die kerk, en hierdie opvatting word ook gesteun deur die siening wat die Nuwe Testament self van die Ou Testa. ment het. Die Ou Testament sien vooruit na die Christus wat sou kom, en die Nuwe Testament kyk terug op die Christus wat gekom het. Die Ou en Nuwe Testamente getuig afsonderlik van mekaar en gesamentlik van Christus.

Hierdie siening is tot sy uiterste konsekwensie deurgedryf deur Wilhelm Vischer in sy "Christuszeugnis des Alten Testaments" (Deel I 1934, Deel II 1942). Die Ou Testament sê wat Jesus Christus is, en die Nuwe Testament wie Hy is. Christus 
is die doel en in 'n sekere sin ook die inhoud van die Ou Testament. As ons Christus nie verstaan soos die Ou Testament van Hom getuig nie, sal ons Jesus nie herken en bely as die Christus nie. Dit is nie baie duidelik wat Vischer presies met die Christus getuienis van die Ou Testament bedoel nie. Soms lyk dit of hy bedoel dat Christus die vervulling van die verwagtings van die Ou Testament is (I, bl. 36). Maar dit word weer anders as hy op verskillende plekke in die Ou Testament Christus in lewende lywe terugvind. Gen. 1 spreek van Christus want $\mathrm{Hy}$ is die een wat in die begin by God was (Joh. 1:1-5). Die teken van Kain wys na die kruis en is hernuwe in die teken van die kruis in die Nuwe Testament. Hos. 11 wys op die lyding van die Seun van die mens. Die duidelikste voorbeeld van die indra van die Nuwe Testament in die Ou Testament vind ons in sy bespreking van die stryd van Jakob by die Jabbok: die geheimsinnige figuur met wie Jakob geworstel het is onteenseglik Jesus Christus self (I, bl. 153). Ehud se swaard wat in die vet buik van die Moabitiese koning wegsak (Rigt. 3), wys op die Woord van God wat skerper is as enige tweesnydende swaard. Die beslissing wat Salomo gae t $\simeq n$ opsigte van die twee vroue wat hulle saak voor hom bring (1 Kon. 3) lei tot die volgende uitleg: Die ware moedar van die lewende kind is die ware Israel, en die verband word gelê met Maria en die kind Josef in die tempel. In regverdigheid teenoor Vischer moet ons wel wys op die motief wat hy met 'n dergelike interpretasie gehad het, waarmee ons wel simpatie kan hê al volg ons hom nie in sy interpretasie nie: Hy wou die Ou Testament bewaar en handhaaf as Woord van God vir die kerk.

Die gevaar is dat die getuienis van die Ou Testament nie beluister word in sy eie aard nie, maar slegs 'n eggo van die Nuwe Testament is. Hy mak geen erns met die geskiedenis en die Goddelike openbaring nie en verval in grootskaalse allegorie (N. W. Porteous, „Old Testament Theology”, in: H. H. Rowley (red.), The Old Testament and Modern Study, Oxford 1956, bl. 339). Dit word bedenklik as elke Ou Testamentiese teks gevra word: wat sê dit oor Christus? Die onbuigsame toepassing van 'n Christologiese maatstaf kan niks anders as allegorie voortbring nie, waardeur die tekste daartoe gebring word om iets anders te sê as wat hulle werklik sê. Die historiese verskil en die inhoudelike andersheid van die twee Testamente word glad nie in aanmerking geneem nie. Dit is iets totaal anders om die eenheid van die Ou Testament en Nuwe Testament vas te hou as om hulle met mekaar te identifiseer of saam te smelt. John Bright (The Authority of the Old Testament, London 1967, bl. 92) sê tereg: „The Old Testament cannot be appealed to as authoritative in the church, or praclaimed with authority, unless its plain 
meaning is adhered to, and adhered to plainly. Once the plain meaning has been abandoned, control over interpretation is gone and Scripture may mean anything the spirit (and who shall say it be the Holy Spirit or the preacher's) may see in it. The sky is the limit!"

\section{DIE EKSISTENSIALISTIESE INTERPRETASIE:}

Hier vind ons ' $n$ ander uiterste in interprestasie. Die vernaamste eksponent van die gedagterigting is Rudolf Bultmann. Hy het sy gedagtes uiteengesit in „Weissagung und Erfüllung” in Glauben und Verstehen, II, Tübingen 1952, bl. 162-186 (tans ook afgedruk in die versamelbundel: C. Westermann, Probleme alttestamentlicher Hermeneutik, München 1960). Vir hom getuig die Ou Testament van die menslike eksistensie onder die wet. Hy verwerp die Ou Testament as boek van profesieë wat in die Nuwe Testament sy vervulling vind. Die moderne metodes van historiese ondersoek het so 'n opvatting onmoontlik gemaak. As die Nuwe Testament 'n voorsegging in die Ou Testament vind, weet ons die Nuwe Testament het dit in die Ou Testament ingelees op grond van die vervulling. Die eerste Christene het dit uit polemiese motiewe teenoor die Jode en uit apologetiese motiewe teenoor die heidene gedoen. Hulle wou die argument vir die verlossing in Christus versterk deur na die oudheid van die Messiaanse profesieë te verwys. Bultmann meen sulke argumente omseil juis die werklike struikelblok: die dwaasheid van die kruis. Dit is maar net poging om die geloof te beveilig. Die geloof kan egter nie gebruik maak van historiese getuienisse dat Christus die doel van die profetiese geskiedenis van Israel is nie.

Hy grond sy beskouinge op 'n studie van drie kardinale Bybelse begrippe: verbond, koningsheerskappy van God en volk van God.

\section{(a) Verbond.}

In die historiese werklikheid is die vervulling van die sedelike eise wat in die verbond gestel word, onmoontlik. Die enkeling as lid van die volk kan nie voldoen aan die voorwaardes van die verbond nie. Daarom kan 'n verbond van God met 'n volk nie 'n empiries-historiese realiteit wees nie, maar alleen 'n eskatologiese begrip. Omdat die ou verbond deur Israel verbreek is, sal God in die komende heilstyd 'n nuwe verbond sluit. Hierdie nuwe verbond is tot stand gebring deur die dood van Christus. In hierdie nuwe verbond is daar nie meer gebeurtenisse in die volksgeskiedenis nie (soos byvoorbeeld die gebeure by Sinaī), want die dood van Christus roep 'n mens puis uit die volksgemeenskap uit in 'n gemeenskap sonder wêreldse gebondenheid. Daarmee het die teenstelling van 'n verbondsvolk tot ander volkere 
weggeval. „Der neue Bund ist eine radikal eschatologische Grösse, d.h. eine ausserweltliche Grösse, und die Zugehörigkeit zu ihm entweltlicht die Genossen des Bundes" (Probleme ...., bl. 41).

\section{(b) Koningsheerskappy van God.}

Soos die koningspsalms in die Ou Testament eskatologiese psalms geword het, so het die koningsheerskappy van God 'n eskatologiese begrip geword. In die ballingskap is die koningsheerskappy van die toekoms verwag. Van die heerlikheid van die heilstyd was daar toe niks te sien nie. In die verkondiging van Jesus is die koningsheerskappy van God 'n wonder wat van die hemel af in 'n nuwe wêreldtyd inbreek. Al wat oorgebly het was die woord „die heerskappy van God" en die gedagte aan 'n gemeenskap waarin God se Naam geheilig word en sy wil geskied. Maar hierdie gemeenskap is nie meer aan die grense van die uitverkore volk gebonde nie (Matt. 8:11v., Luk. 10:30-37), en is nie „,innerweltlich realisierbar” (Probleme, bl. 44) nie. „Die Herrschaft Gottes bzw. Christi ist also etwas völlig anderes, als die alttestamentliche Prophetie erwartet hatte. Sie ist völlig eschatologisch - überweltlich, und der Mensch, der an ihr teilhat, ist gleichsam schon entweltlicht, so das er, wiewohl noch ,im Fleisch', doch nicht ,nach dem Fleische' lebt (2 Kor. 10:3)"' (Probleme, bl. 45).

\section{(c) Volk van God.}

Hy illustreer aan die gang van die Israelities-Joodse geskiedenis die innerlike teenstrydigheid tussen die gedagte van 'n Godsvolk en 'n empries-historiese volk met 'n selfstandige staatsbestaan. Die identifikasie van die twee is vir hom 'n illusie. In die Nuwe Testament is die volk van God, die ware Israel, aanwesig in die Christelike gemeente. Die volk van God is nie meer 'n empiries-geskiedkundige grootheid nie; die ware Godsvolk as ekklesia is 'n eskatologiese begrip. 'n Mens behoort nie daaraan deur geboorte of volksverbondenheid nie, maar deur die roepstem van die Evangelie wat jou uit die wêreld uitroep. Hy wys daarop dat die Jode in die Openbaringe selfs uitgeskakel word vir die sinagoge van die satan.

Die verhouding tussen die belofte (Weissagung) in die Israelities-Joodse geskiedenis en die vervulling daarvan in die Nuwe Testament bestaan alleen ,,in ihrem inneren Widerspruch, in ihrem Scheitern" (Probleme, bl. 50). Sowel die gedagte van 'n verbond van God met 'n volk, as die idee van die konings-heer . skappy van God en van 'n Godsvolk in 'n empiriese volksgemeenskap blyk onrealiseerbaar. Vanuit Bultmann se opvatting van die eskatologie is daar vir hom dus geen kontinuiteit tussen die geskiedenis van Gods volk in die Ou Testament en die nuwe volk 
van God in die Nuwe Testament nie. „Das Scheitern erweist die Unmöglichkeit, und deshalb ist das Scheitern die Verheissung. Für den Menschen kann nichts Verheissung sein als das Scheitern seines Weges, als die Erkenntnis der Unmöglichkeit, in seiner innerweltlichen Geschichte Gottes direkt habhaft $\mathrm{zu}$ werden, seine innerweltliche Geschichte direkt mit Gottes Handeln zu identifizieren", (Probleme, bl. 51). God het die volk van die Ou Testament op die weg van mislukking as belofte (,,Scheitern als Verheissung") gelei, maar hierdie teenstrydigheid is ook eie aan die menslike eksistensie as sodanig: ,auf Gott hin geschaffen zu sein, zu Gott gerufen zu sein und doch der weltlichen Geschichte verhaftet zu sein" (a.w., bl. 52). Deur die geskiedenis van die Ou Testament op hierdie wyse te interpreteer, volg ons Paulus se interpretasie van die wet as tugmeester na Christus toe (Gal. $4: 24)$.

'n Groot beswaar teen die opvatting van Bultmann is dat hy die antitese van wet en evangelie so ver deurdryf dat hy die Ou Testament aan die wet gelykstel. Die diskontinuïteit tussen Ou en Nuwe Testament word oorbeklemtoon, en die Ou Testament is van minder belang as dit maar net 'n pedagogiese funksie het om mense vir die evangelie voor te berei. As dit aan die hoorder 'n verstaan van sy eksistensie bied, is daar nie ander moontlikhede as die Ou Testament om hierdie funksie te vervul nie? Bultmann impliseer dit self as hy daarop wys dat sommige van die geskrifte van die Nuwe Testament min van die Ou Testament gebruik maak. Kortom, Bultmann se benadering toon hoogstens die nuttigheid van die Ou Testament vir die prediking, en nie die noodsaaklikheid daarvan nie.

\section{DIE „FRÖMMIGKEITSGESCHICHTLICHE” OF GODSDIENS-}

\section{HISTORIESE BENADERING.}

'n Sekere affiniteit met die voorafgaande beskouing vertoon die gedagte van Friedrich Baumgärtel (,Das hermeneutische Problem des Alten Testaments," in die reeds genoemde versamelbundel, bl. 114 vv.).

Die Christen verstaan die Ou Testament vanuit „seinem Ergriffensein durch das Evangelium von Jesus Christus" as getuienis van Jesus Christus (Probleme, bl. 114). Hy verstaan dit dus vanuit die geloof, en op 'n ander wyse as wat die mens van die Ou Testament die woord van die Ou Testament verstaan het. Vanuit homself is die Ou Testament godsdienshistories en „frömmigkeitsgeschichtlich", maar nie teologies nie, verstaanbaar. Dit bly 'n vreemde woord uit 'n vreemde godsdiens, waarvan ons die krag wel kan aanskou, maar wat ons nie raak nie. Dit het mag gehad oor die Ou-Testamentiese mense, ,sein Verstehen war 
aber alttenstamentlich, ausserhalb des Evangeliums und deshalb nicht unser Verstehen d.h. unser Ergriffensein durch das alttestamentliche Zeugnis" (a.w., bl. 114). In die evangeliese, dit wil sê Christelik-gelowige verstaan van die Ou Testament is die Ou Testament te akkomodeer as die Ou-Testamentiese, uit destyds en vir destyds, as woord buite die evangelie. Die Ou Testament moet die oue bly. Die Christologiese en tipologiese verstaanswyses is nie geskik nie, want dit neem die woord van die Ou Testament nie in sy „Selbstverständnis” in die evangelie in nie.

Hy betoog verder dat daar duidelik gemaak moet word hoe die Ou-Testamentiese getuienis op die mens van die Ou Testament en Nuwe Testament tegelyk ,wirkende Mächtigkeit" het. Die OuTestamentiese Woord is wel te verstaan as evangelie, maar in sy beperktheid as woord buite die eintlike evangelie. Die gemeenskaplike wortel van die getuienis van die Ou Testament en Nuwe Testament is die basiese belofte („Grundverheissung”): „Ek is die HERE jou God", „,das Alte Testament glaubend harrend auf ihr Wahrwerden, das Neue Testament glaubend wissend, dass sie in Jesus Christus wahr geworden ist" (a.w., bl. 133).

As woord buite die evangelie bring die Ou Testament vir ons troos, want Christus het ons lankal uit dié woorde met hulle bindinge en begrensdheid weggeneem. Ons kom in die kragveld van die evangelie as ons begryp dat die getuienis van die $\mathrm{Ou}$ Testament afgehandel is. Ons het byvoorbeeld nie meer nodig om reg te roep soos die bidder in Ps. 26 nie, want God het ons lankal in Christus ons reg geskenk. Ons hoef nie meer met die OuTestamentiese vyandspsalms te ywer vir die triomf van God oor die vyande nie, want God se triomf is lankal in die kruis en opstanding van Christus openbaar. Die Ou Testament word vir ons 'n blye boodskap terwyl dit ons van ons gebrokenheid voor God oortuig.

Ons word dus getroos deur die Ou Testament as afgedane Woord. Maar daar is ook 'n heilshistoriese lyn. Vanuit die evangelie is dit die heilsgeskiedeins: „die Woord het vlees geword". Die Ou-Testamentiese gebeure hoort binne hierdie "Woord-het-vlees-geword". As heilshistoriese gebeure kan die Ou Testamentiese gebeure net in soverre begryp word as wat dit ons eksistensie voor God "fragwürdig" maak en ons in ons bestaan (a.w., bl. 136). By die gebeure in Ou Testament en Nuwe Testament vind daar ook 'n ,inneres Geschehen" plaas. Hierdie innerlike gebeure en die houding van die Ou Testamentiese vrome onder hierdie gebeure moet ons deur middel van ,frömmigkeitsgeschichtliche" andersoeke naspeur. Eers wanneer dit gedoen word, kan ons vasstel "inwiefern dieses Getroffensein des 
alttestamentlichen Menschen unsere eigene Existenz vor Gott anrührt, inwiefern diese Getroffensein unser eigenes Getroffensein . . . unter dem Evangelium ist" (a.w., bl. 136).

In Baumgärtel se siening is die Ou Testament nie herroep nie, inteendeel, dit word noodsaaklik vir die geloof beskou. Hy maak ook nie die Ou Testament los van die Nuwe Testament as sou die Ou Testament mindere gesag het nie. Hy sien die verhouding tussen die Ou Testament en die Nuwe Testament nie as een van volkome diskontinuinteit nie. Tog word die verskil tussen die Ou Testament en Nuwe Testament baie sterk beklemtoon, wanneer hy die Ou Testament sien as getuie van 'n ander godsdiens as die Christelike. Het die Ou Testament dan nie ook maar net 'n pedagogiese funksie nie, en is dit nog noodsaaklik?

\section{DIE „TEOLOGIESE” INTERPRETASIE.}

John Bright het nie hierdie naam aan sy interpretasiewyse gegee nie en van sy werkwyse sê hy in sy Authority of the Old Testament: "the point can better be illustrated than argued". Hy wil 'n hermeneutiek vermy wat die relevansie van die prediking in gevaar bring. Hy sien 'n gevaar in die tipologiese metode op grond van die misbruike wat dit moontlik maak. Dit laat ook nie reg aan die $\mathrm{Ou}$ Testamentiese geskiedenis geskied nie. Wat maak ons met gedeeltes waar analogieë tussen Ou Testament en Nuwe Testament nie gesien kan word nie? Sy beswaar teen die sogenaamde Heilsgeschichte en die toepassing van 'n skema van belofte en vervulling is dat die gevaar bestaan dat die prediking verhaal (,rehearsal of past events") word, waarby die hoorders as toeskouers mag staan en alleen informasie ontvang. Die prediking van die Ou Testament moet die hoorder egter betrek. Hy moet die geskiedenis van die Ou Testament sien as sy geskiedenis, en die beloftes daarvan as sy beloftes. Hy vra die vraag: „Do we stand before the door of the Old Testament without a key?" (bl. 197). Hierdie sleutel vind hy in die teologiese struktuur van die twee Testamente. Hy wil nie 'n ander formulering bring vir die verhouding tussen die twee Testamente nie, want die verhouding is te kompleks. Hy stel dit dan dat die Bybel deur sy teologie spreek en dat die teologie outoriteit meebring. Ons moet die teologie van 'n bepaalde gedeelte van die Ou Testament vasstel en dit opnuut uitdruk vir die mense van ons tyd. Alles geld vir ons, want ten spyte van die aard en boodskap van elke gedeelte, of dit na aan die kernboodskap van die Ou Testament is of verder, dit reflekteer of gee uitdrukking aan die teologiese struktuur daarvan. „There are no none-theological texts in the Bible" (Authority, bl. 152). 
Hy bied verskillende illustrasies vir sy standpunt. 'n Enkele voorbeeld: Dit gaan in Lev. 25 om die grondbesit van die familie in verband met die Jubeljaar. Die teologie wat aan die daar vermelde wet ten grondslag lê is die volgende: Die land behoort aan God, daarom leef ons op die aarde as vreemdelinge en bywoners. Wat ons het, het God aan ons geleen. As ons besigheidstransaksies doen moet ons dit doen in die vrese van die Here en genadig wees teenoor ons medebroers as mense wat self genade ontvang het. Die gedeelte is relevant vir die Christen, want Christus se geregtigheid het die wet vervul en ons is gehoorsaamheid verskuldig aan sy gebod van die naasteliefde. Ons kan nie die wet van die Jubeljaar gehoorsaam nie, maar ons kan die teologie van die wet aktualiseer.

Die uitleg word bereik langs die weg van die grammatikaalhistoriese eksegese van die teks. Ons soek die letterlike betekenis van die teks en daarin en daaragter die teologiese belang: die teologiese doel van die historiese verhaal, die teologiese oortuiging agter die profetiese uitspraak, die wyse waarop Israel se geloof in God uitgedruk is in 'n bepaalde psalm, watter funksie dit in die lewe van die individue of die gemeenskap het. Maar omdat die Christen die Ou Testament uit die hande van Christus ontvang het, wat die vervulling daarvan is, bring hy die Ou Testamentiese teks na die Nuwe Testament. Wat het die Nuwe Testament gedoen met hierdie aspek van die geloof van die Ou Testament in die lig van Christus? Gaan dit om vervulling? Vind ons 'n oorname, net so of met 'n verandering? Kry dit 'n totaal nuwe betekenis, word 'n oordeel daaroor uitgespreek of word dit herroep? Daar moet gelet word op die "existential placement of the text", die eksegeet „has the task of re-aiming his text" (a.w., bl. 212). Die menslike situasie het essensieel dieselfde gebly.

Naas hierdie standpunte is daar vele ander wat basies verskillend is of variasies op die bespreekte tema's bevat. Daar is selfs uit die kringe van die Wêreldraad van Kerke 'n lekepublikasie (van 'n leek op die gebied van die Ou Testamentiese wetenskap, nie vir leke nie!) met die pretensieuse titel: The indispensable Old Testament, deur G. H. Wolfensberger. Die werk bly deurgaans op die sosiale vlak en daarom op die oppervlakte. Teologiese literatuur is dit nie en ons het ons in hierdie artikel met wetenskaplik-teologiese literatuur besig gehou. Maar ook hierdie kuriositeit tesame met al die wetenskaplike verantwoorde opvattings toon die toenemende belangstelling vir die Ou Testament, sy verhouding tot die Nuwe Testament en in die lig hiervan, sy relevansie vir die Christelike prediking. 